\title{
UTILIZAÇÃO DO TELEVISIONAMENTO ÓPTICO DE FUROS DE SONDAGEM NA AVALIAÇÃO DA ESTABILIDADE DE TALUDES EM DEPÓSITOS DE FERRO
}

\author{
USE OF OPTICAL IMAGING OF BOREHOLES IN THE EVALUATION \\ OF SLOPE STABILITY IN IRON ORE DEPOSITS
}

DOUGLAS MARCEL QUATIABARA SANDER LIBARDI Universidade Federal do Rio Grande do Sul, Porto Alegre - RS, Brasil. quatiabara@gmail.com

PAULO SALVADORETTI Universidade Federal do Rio Grande do Sul, Porto Alegre - RS, Brasil. paulo.salvadoretti@ufrgs.br

GEORGE OLUFUNMILAYO GASPER Universidade Federal do Rio Grande do Sul, Porto Alegre - RS, Brasil. gee_mailz@yahoo.com

OLUWAFEMI SHEKONI AYODEII Universidade Federal do Rio Grande do Sul, Porto Alegre - RS, Brasil. shekony@yahoo.com

ANDRÉ CEZAR ZINGANO Universidade Federal do Rio Grande do Sul, Porto Alegre - RS, Brasil. andrezin@ufrgs.br

JOÃO FELIPE COIMBRA LEITE DA COSTA Universidade Federal do Rio Grande do Sul, Porto Alegre - RS, Brasil. jfelipe@yahoo.com

ELIAS KASPARY POOTER Universidade Federal do Rio Grande do Sul, Porto Alegre - RS, Brasil.e_pooter@hotmail.com

\begin{abstract}
RESUMO ABSTRACT
O Optical Televiewer (OTV) é um dispositivo de perfilagem geofísica que produz uma imagem contínua e orientada da parede de furos de sondagem. Neste trabalho, foram selecionadas imagens obtidas em furos de sondagem executados em duas jazidas de ferro que fazem parte da 'Megaestrutura Gandarela', localizada na porção centro-norte do Quadrilátero Ferrífero, Estado de Minas Gerais, Brasil. As imagens geradas com OTV desempenham um papel auxiliar em campanhas de exploração mineral e também na aquisição de informações geotécnicas. No presente estudo, os dados de OTV coletados em taludes de duas minas a céu aberto serviram para efetuar-se a identificação e orientação (dip e dip direction) das estruturas geológicas, a correção da declinação magnética das estruturas e análises cine-

The Optical Televiewer (OTV) is a geophysical logging device that produces a continuous and oriented image of the borehole wall. In this study, images obtained from boreholes collected at two iron deposits that are part of the 'Mega Structure Gandarela', located in the north-central portion of the Quadrilátero Ferrífero, State of Minas Gerais, Brazil, were selected. The images generated with OTV play an auxiliary role in mineral exploration survey and also in the acquisition of geotechnical information. The OTV data collected on slopes of two open pit mines served to carry out the identification and orientation (dip and dip direction) of the geological structures, the correction of the magnetic declination of the structures and kinematic analyzes indicating the possible types of rupture of
\end{abstract}


máticas indicando os possíveis tipos de ruptura dos taludes, as quais foram realizadas nos softwares WellCad e Dips. O principal objetivo é comparar as estruturas identificadas via OTV em furos de sondagem em relação as já observadas nos levantamentos de superfície, de modo a verificar se o comportamento das estruturas locais permanece inalterado em profundidade. $\mathrm{O}$ estudo mostrou que mesmo dispondo-se de um número limitado de furos de sondagem, as estruturas em profundidade marcadas com OTV servem como um importante complemento às observações feitas a partir dos mapeamentos geológicos estruturais de superfície.

Palavras-chave: geofísica, optical televiewer, minério de ferro.

\section{INTRODUÇÃO}

O televisionamento de furos de sondagem é uma técnica relativamente nova. Foi introduzida no Brasil no ano de 2001 (Baillot et al., 2004) e apresenta-se hoje como uma técnica auxiliar na análise de problemas geológico-geotécnicos (Oliveira, 2015).

O Optical Televiewer (OTV) é um dispositivo de televisionamento que produz imagens contínuas e orientadas da parede de furos de sondagem. O uso de imagens de OTV é prática internacionalmente conhecida na identificação de feições geológicas dos estratos (Fredrick et al., 2014). De acordo com Blake (2010) e Baillot (2012), a combinação da técnica de sondagem com circulação reversa (sondagem $\mathrm{RC}$ ) e o televisionamento de furos pode levar a uma redução significativa dos custos da pesquisa mineral, reduzindo a necessidade de extração de testemunhos com sondagem rotativa convencional e o uso da sondagem orientada. Desta forma, as imagens geradas com OTV desempenham um papel auxiliar em campanhas de exploração mineral e também na aquisição de informações geotécnicas.

Neste trabalho, é feita uma aplicação de imagens de OTV em furos de sondagem rotativa convencional, executados em duas jazidas de ferro (minas de Gongo Soco e Tamanduá), localizadas na porção centro-norte do Quadrilátero Ferrífero, no Estado de Minas Gerais. Em função da necessidade de serem coletados dados geotécnicos com- the slopes, which were performed helped by softwares WellCad and Dips. The main objective is to compare the structures identified via OTV in boreholes to those already observed in surface surveys, in order to verify if the behavior of local structures remains unchanged in depth. The study showed that even with a limited number of drillholes, the deep structures marked with OTV serve as an important complement to the observations made from the structural geological surface mappings.

Keywords: geophysics, optical televiewer, iron ore.

plementares de taludes finais nestas duas minas, novos furos de sondagem foram perfurados, com posterior aquisição de imagens de OTV. Estudos anteriores feitos nestas minas serviram para definir seus respectivos modelos de comportamento lito-estrutural. Levantamentos estruturais de superfície foram realizados ao longo da vida útil dos empreendimentos, os quais revelaram muitos detalhes a respeito das características geotécnicas das rochas presentes nestas áreas.

No presente estudo, o principal objetivo é comparar as estruturas identificadas via OTV em furos de sondagem em relação as já observadas nos levantamentos de superfície, de modo a verificar se o comportamento das estruturas locais permanece inalterado em profundidade. Além disso, é feita uma análise cinemática em alguns taludes de interesse em ambas as minas, a partir de estruturas marcadas em imagens de OTV, comparando-a com a análise cinemática efetuada a partir das estruturas identificadas no mapeamento geológico estrutural de superfície, para verificar se houve mudanças que poderiam resultar em novas possibilidades de ruptura desses taludes.

\section{OPTICAL TELEVIEWER}

A técnica de perfilagem geofísica consiste na passagem de dispositivos contendo sensores dentro de furos de sondagem, efetuando-se medições de várias propriedades físicas das rochas adjacentes ao furo de sondagem. 
No caso específico da aquisição de imagens de OTV, é feito um imageamento radial da parede do furo, obtendo-se imagens orientadas no espaço. Esta orientação possibilita uma análise cuidadosa das estruturas geológicas de interesse. Tipicamente, os dados são exportados para a confecção, por exemplo, de estereogramas das estruturas. Eventualmente, as imagens são usadas para gerar outras informações adicionais com respeito aos perfis (p. ex. frequência de fraturas).

Durante a perfilagem, os dados adquiridos incluem o registro de inclinação e azimute do furo, nível de iluminação das imagens, resolução, velocidade de aquisição, temperatura, radiação gama natural emitida pelas rochas, entre outros parâmetros.

O OTV gera imagens da parede do furo com alta resolução (até 1 milímetro, aproximadamente). As aplicações para este tipo de dispositivo incluem inspeções de defeitos em revestimentos, caracterização de fraturas em furos preenchidos tanto com ou sem água, entre outras. Esta sonda, quando combinada com outros sensores mais tradicionais, pode ser usada para observar variações mineralógicas e estudos de foliação das rochas ao longo de furos de sondagem.

Imagens adquiridas com televiewer são orientadas através da coleta simultânea de dados das componentes tridimensionais do campo magnético terrestre e componentes tridimensionais de inclinação do furo, incorporados no OTV, essenciais para a interpretação. A imagem possui uma direção referencial comum, geralmente o norte magnético. Estruturas planares que intersectam a parede do furo produzem traços senoidais na imagem do televiewer projetadas ("desembrulhada") (Figura 1). Usando a direção referencial gravada durante a perfilagem, senóides podem ser analisadas para a produção de características estruturais de mergulho (dip) e da direção mergulho (dip direction) das estruturas em profundidade.

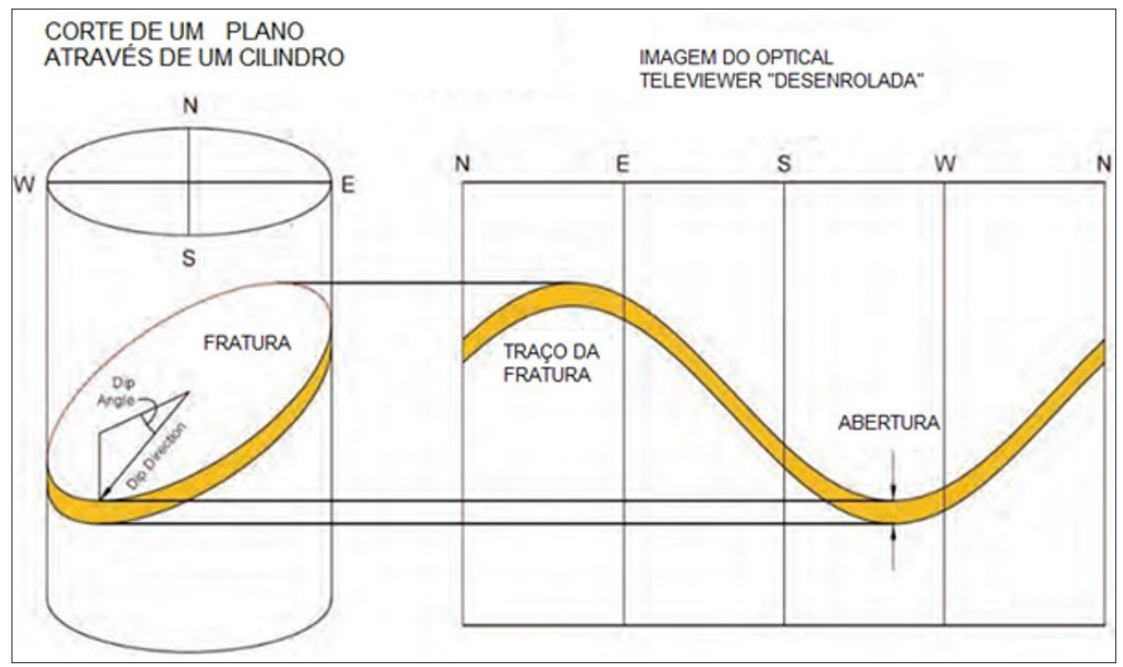

Figura 1. Formação e orientação da imagem gerada por OTV.

Fonte: Robertson, 2014.

A definição de dip e dip direction a partir das imagens abertas de OTV pode ser vista na Figura 2. Conforme Chung et al. (2008), as imagens geradas com televiewers resultam em imagens contínuas e orientadas de $360^{\circ}$ da parede do furo a partir da qual a relação, a orientação da litologia e/ ou as características planares estruturais podem ser definidas.
Um exemplo de imagem em minério de ferro encontra-se na Figura 3, a qual apresenta litologias friáveis. Percebe-se que a imagem gerada com OTV mostra uma fratura no maciço rochoso na profundidade de $14,3 \mathrm{~m}$, a qual não pode ser observada na caixa de testemunhos. A orientação de características estruturais planares visíveis com OTV é geralmente local, e pode não represen- 
tar a tendência global da estrutura na rocha. Isto é superado quando, na área de interesse, estiver disponível um número suficiente de furos de sondagem, de tal forma que exista uma amostragem estatística das estruturas.

Outra funcionalidade do OTV é que ele pode fornecer valiosas informações, com foco principal no posicionamento espacial (dip e dip direction) de descontinuidades e outras estruturas (veios, bandamentos, acamadamentos), quando estas são feições identificáveis. Conforme Gwynn et al.(2013) e Thomas et al.(2015) o erro previsto na determinação da posição espacial destas feições, considerando a técnica de sondagem orientada, pode chegar a $13^{\circ}$, enquanto que o OTV apresenta um erro cumulativo de $\pm 1,7^{\circ}$ para o dip e $\pm 4^{\circ}$ para o dip direction. Assim, é uma ferramenta de grande auxílio na construção de estereogramas e na análise de estabilidade cinemática.

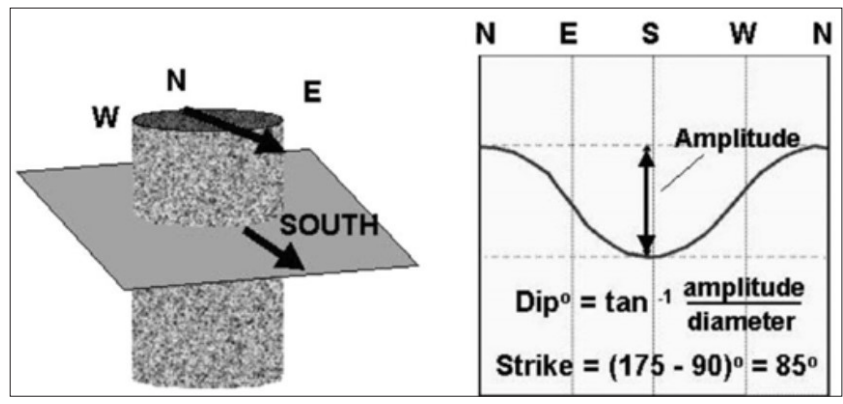

Figura 2. Tensão Crítica x Perda de Solo Para Amostra Natural.

Fonte: Retirado de Chung et al., 2008.

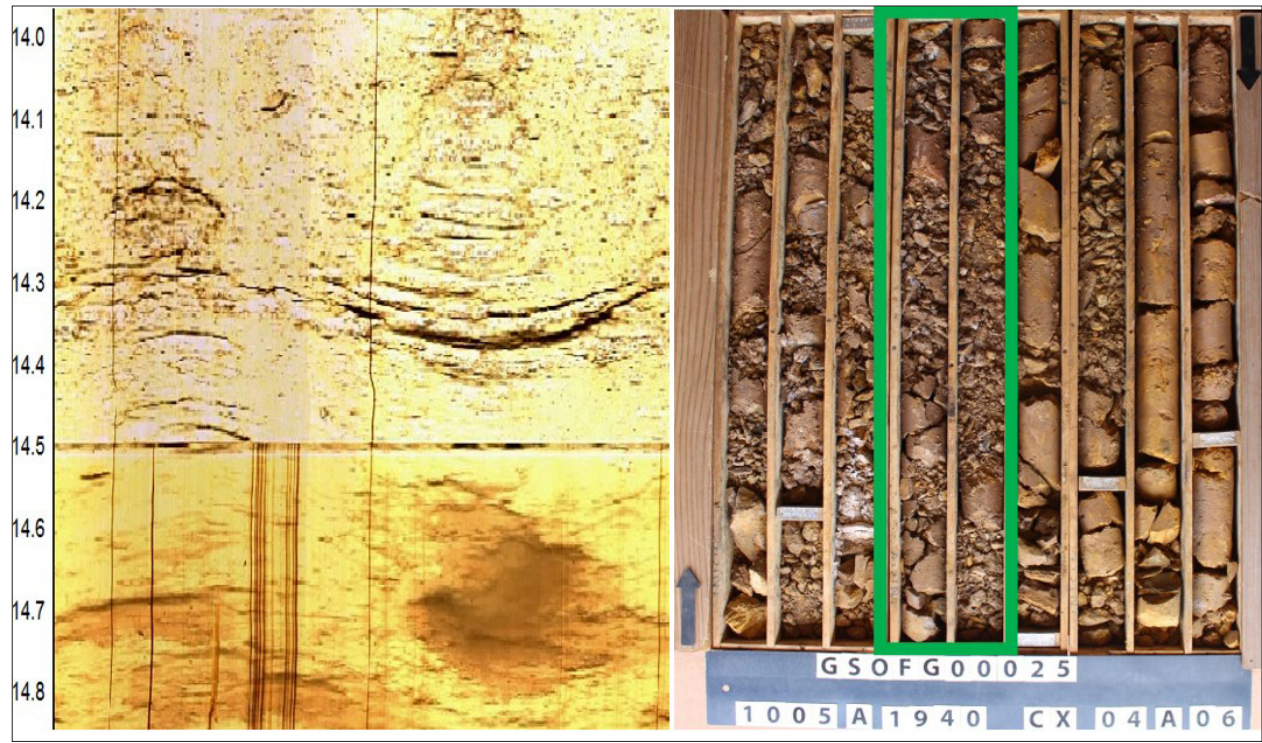

Figura 3. Imagem de fratura em litologias friáveis (à esquerda), ao lado da foto de testemunhos de sondagem (à direta). O fraturamento é visível somente no televisionamento. (Nível d'água em 14,5m).

Fonte: ?

As principais vantagens no uso dos métodos e observações do Optical Televiewer incluem:

- Redução potencial no esforço de sondagem testemunhada;

- As imagens permitem ver claramente as zonas de baixa recuperação e intenso fraturamento in-situ - o equivalente a 100\% de recuperação pode ser alcançada;

- Perfilagem com OTV é relativamente barato para se realizar e é altamente portátil, permi- tindo que a técnica seja utilizada em terrenos difíceis;

- Sondagem testemunhada exige várias operações repetitivas que muitas vezes acabam sendo registradas como uma série de segmentos entre paradas ou execuções, enquanto que o OTV fornece um registro contínuo do furo com profundidade e referências mais precisas; 
- Dados gravados como informações de estruturas marcadas sobre as imagens podem ser importados diretamente para aplicações de softwares de análise cinemática;

- Possibilidade de estabelecer a orientação espacial verdadeira das estruturas visualizadas, evitando o uso de sondagem orientada, a qual apresenta maiores custos.

\section{LOCALIZAÇÃO E ASPECTOS GEOLÓGICOS DAS ÁREAS DE ESTUDO}

Neste estudo, foram utilizados furos de sondagem executados em minas que fazem parte da 'Megaestrutura Gandarela', localizada na porção centro-norte do Quadrilátero Ferrífero, Estado de Minas Gerais - Brasil (Figura 4).

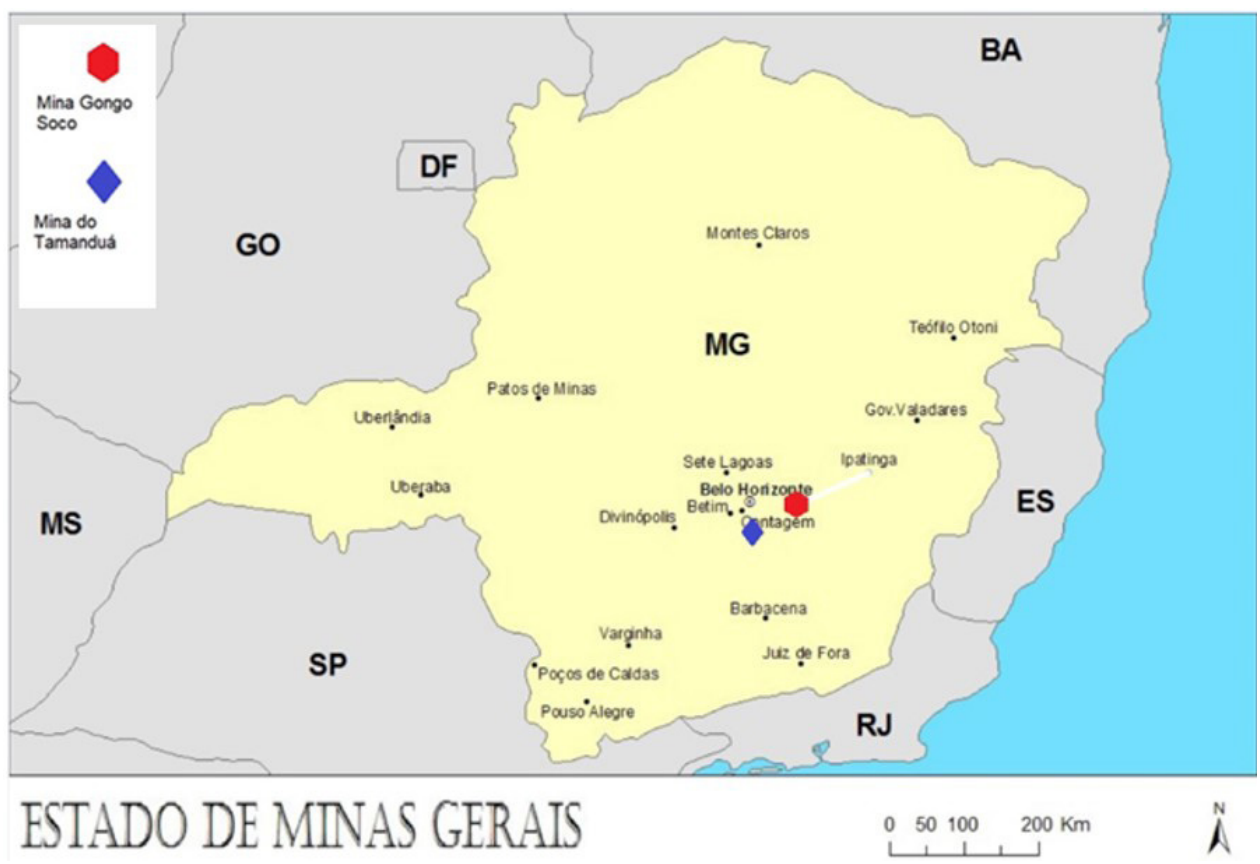

Figura 4. Localização das áreas de estudo (Mina Gongo Soco e Mina Tamanduá). Fonte: ?

\subsection{Geologia local - Mina Gongo Soco}

A geologia da Mina Gongo Soco, onde encontram-se três furos filmados com OTV, apresenta como principais litologias aflorantes: solo saprolítico, rocha intrusiva metabásica, hematitas, itabiritos, quartzitos, filitos e xistos (Anon., 2008).

A geologia estrutural da área, obtida em mapeamentos feitos diretamente sobre o terreno (Anon., 2008) identifica várias estruturas planares e lineares, sendo as mais importantes: bandamento $(\mathrm{Sb})$, foliação $(\mathrm{Sn})$, clivagem de fratura $(\mathrm{Sn}+1)$, famílias de fraturas (Fr) presentes nas rochas metabásicas (IN), lineação de intersecção (Li) e eixo de dobra (bn).

O bandamento ( $\mathrm{Sb}$ ) é a estrutura principal e condicionante da estabilidade dos taludes na
Mina Gongo Soco, sendo possível sua identificação em quase todas as litologias da cava.

Outra estrutura penetrativa observada em praticamente todos os litotipos é a foliação Sn. A geração da Sn pode estar associada tanto a processos cisalhantes como a dobramentos.

Em se tratando de fraturas, de uma maneira geral, as juntas apresentam persistência métrica. Suas superfícies são predominantemente lisas e onduladas, fechadas, sem preenchimento e com espaçamento pequeno a moderado (centimétrico e decimétrico).

Note que o bandamento $\mathrm{Sb}$, a foliação $\mathrm{Sn}$ e as fraturas são as estruturas possíveis de visualização com o OTV, sendo que este fato é levado em conta nas análises realizadas neste trabalho. 


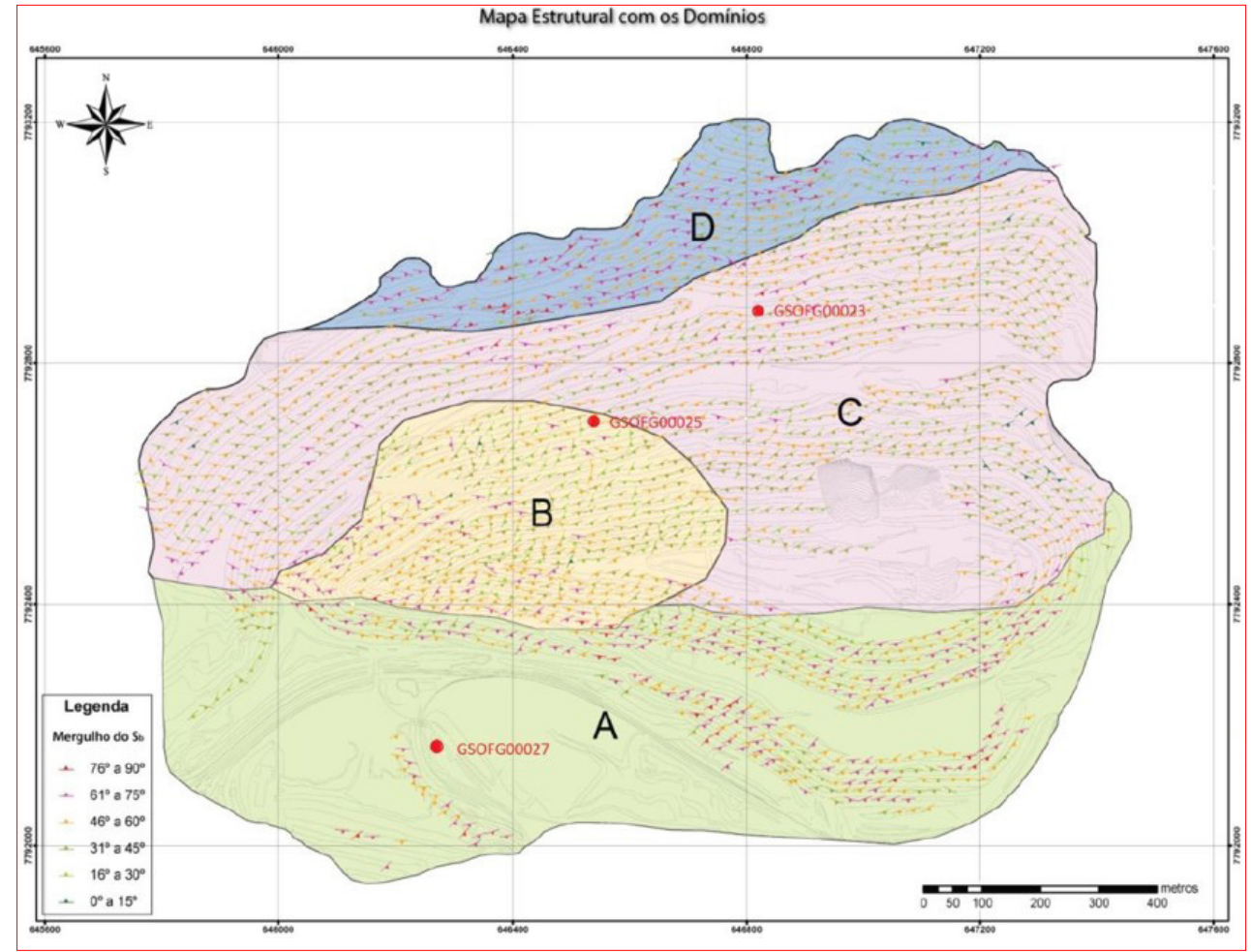

Figura 5. Mapa dos Domínios Estruturais da Mina Gongo Soco, com a localização dos três furos imageados com OTV. As letras A, B, C e D representam as regiões dos 4 domínios estruturais existentes na Mina Gongo Soco.

Fonte: Anon., 2008.

\subsection{Geologia local - Mina Tamanduá}

A Mina Tamanduá posiciona-se na região centro-norte do Quadrilátero Ferrífero e se insere no domínio geológico do Supergrupo Minas, representado pelos quartzitos da Formação Moeda e filitos da Formação Batatal (Grupo Caraça) e formações ferríferas da Formação Cauê (Grupo Itabira). Na Mina Tamanduá, foram adquiridas imagens de OTV em dois furos, assinalados na Figura 6.

Segundo Anon. (2012), a cava atual desta mina é constituída predominantemente por itabiritos friáveis (IF, IGO), itabiritos médios (IM), itabiritos compactos (IC), filitos e quartzitos, com presença subordinada de hematitas, itabiritos argilosos (IAL, IMN), rochas intrusivas e metavulcânicas.
Em termos de estruturas geológicas existentes na área, foram identificados os seguintes elementos (Anon., 2012): o acamamento S0 (observado nos filitos e quartzitos da encaixante), o bandamento composicional $\mathrm{Sb}$, a foliação $\mathrm{Sn}$ e as superfícies de cisalhamento Scis.

\section{RESULTADOS}

Após a aquisição de dados em campo, as imagens de OTV foram analisadas de modo a permitir a marcação de estruturas geológicas, correção da declinação magnética e análises cinemáticas, o que foi efetuado com a utilização dos softwares Wellcad e Dips. 


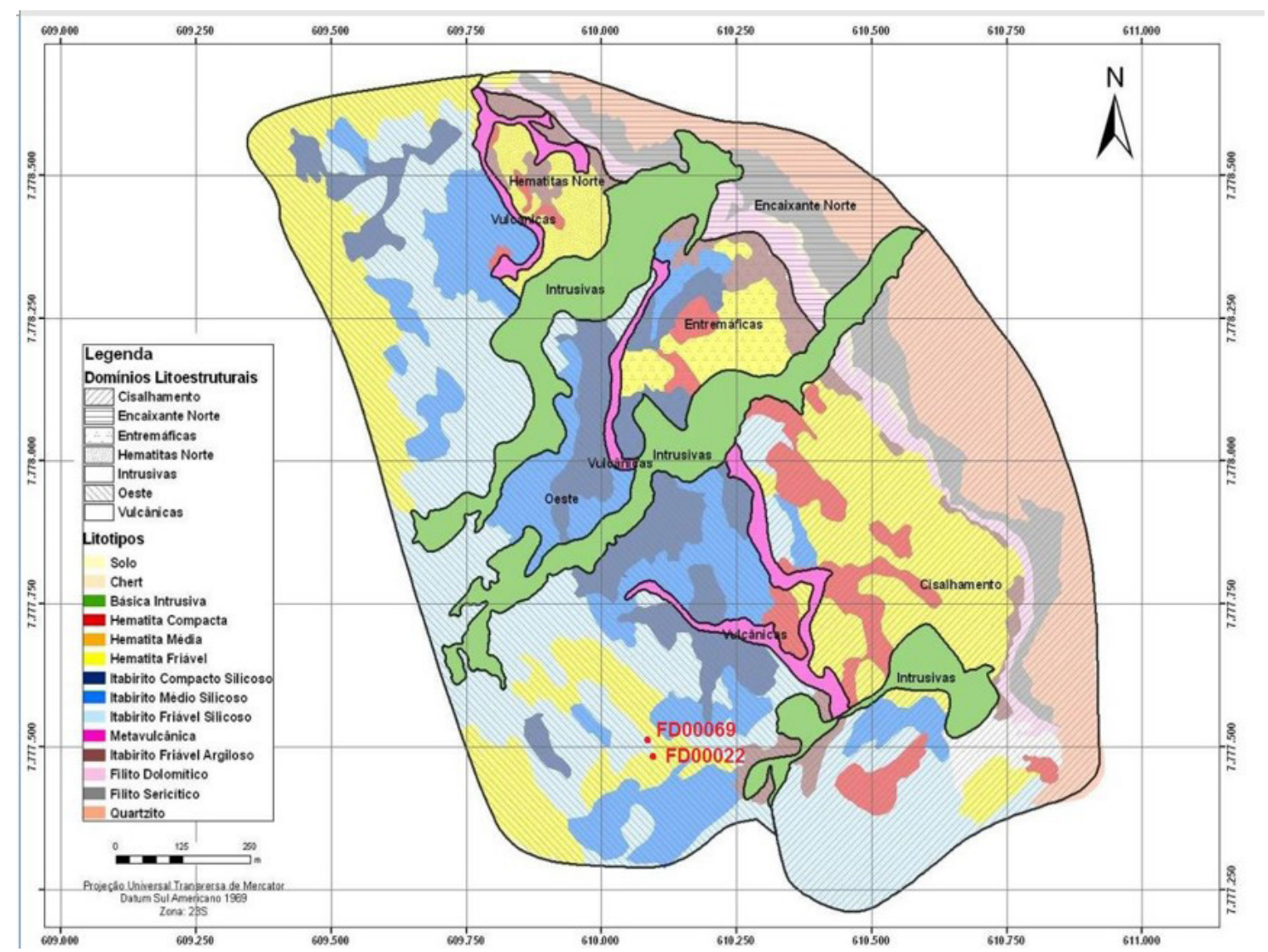

Figura 6. Representação da Mina Tamanduá. Os furos televisionados encontram-se no Domínio Oeste e entre os Subdomínios de Hematita Friável e Itabirito Friável Silicoso.

Fonte: ?

\subsection{Estereogramas das feições observadas}

\section{Mina Gongo Soco}

Com base nas imagens de OTV, foram confeccionados estereogramas, consistindo de bandamentos e fraturas marcadas nestas. No furo GSOFG00023, foi possível obter, contabilizando-se todas as estruturas visíveis nas imagens, um total de 86 marcações. Os furos GSOFG00025 e GSOFG00027 contabilizaram 101 marcações e 14 marcações, respectivamente. Considerando as estruturas visíveis nos 3 furos, obteve-se um total de 201 marcações. A título de comparação, vale salientar que a quantidade de dados adquiridos em levantamentos de superfície feitos em Gongo Soco para a realização das análises foi de aproximadamente 1300 pontos, os quais foram usados para definir as estruturas principais da mina.

Comparando-se os estereogramas gerados pela análise de dados de OTV com os dados de levantamentos de superfície gerados em Anon. (2008) para bandamento e foliação (estruturas principais), pode-se notar boa semelhança visual entre os mesmos (ver Figura 7). Tem-se então um forte indicativo de que as estruturas observadas nos levantamentos em superfície se repetem em profundidade, sendo esta uma informação importante buscada na análise de imagens de OTV.

Pode-se perceber, na Figura 7, que a soma das marcações dos três furos em apenas um estereograma revela grande semelhança com as estruturas principais apontadas em Anon. (2008), em especial com a dip direction da foliação. Ainda que nas marcações de estruturas realizadas nas imagens de OTV não seja possível discernir entre as estruturas Bandamento e Foliação, apenas podendo-se diferenciar fraturas das outras estruturas, pode-se afirmar que as estruturas demarcadas nas imagens tendem a indicar diretamente a presença e continuidade das estruturas principais no interior dos taludes. 


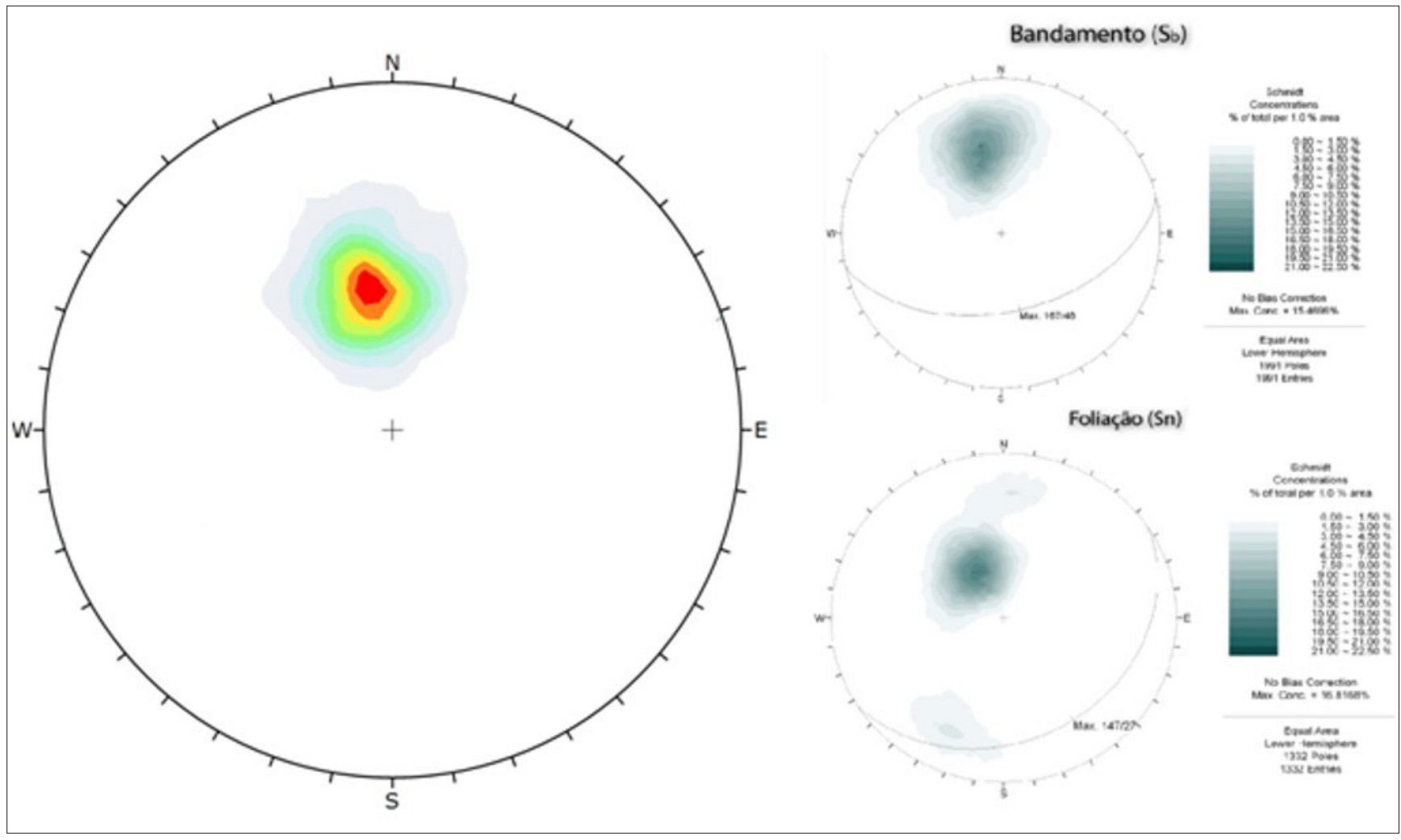

Figura 7. Estereograma mostrando os dados obtidos por OTV (à esquerda) e as duas estruturas principais na Mina Gongo Soco (à direita).

Fonte: ?

\section{Mina Tamanduá}

Para a Mina do Tamanduá, ao se comparar os estereogramas gerados em Anon. (2008) das estruturas principais e os estereogramas gerados pela análise de imagens de OTV, nota-se uma boa semelhança visual estes (Figura 8). Para comparação, a quantidade de dados adquiridos em Anon. (2012) para a realização das análises dos levantamentos de superfície foi de mais de 1500 pontos, definindo assim quais são as estruturas principais da Mina do Tamanduá. Por outro lado, no furo TAMFD00022 conseguiu-se um total de 31 marcações com OTV, contabilizando todos os tipos de estruturas, e para o furo TAMFD00069 obteve-se um total de 71 marcações. Somando os dois furos, chega-se a um total de 102 marcações a partir de OTV.

Percebe-se, na Figura 8, que existem boas semelhanças entre as estruturas marcadas com OTV e as estruturas principais apontadas em levantamentos de superfície (Anon., 2004 e 2012), em especial quanto ao dip/dip direction do acamadamento. Como frisado anteriormente, as imagens de OTV não permitem discernir entre as estruturas acamadamento $\left(\mathrm{S}_{0}\right)$, bandamento $(\mathrm{Sb})$ e foliação (Sn), mas pode-se afirmar que tais estruturas tendem a produzir fraturas, as quais por sua vez tendem a ser visíveis nas imagens de OTV. 


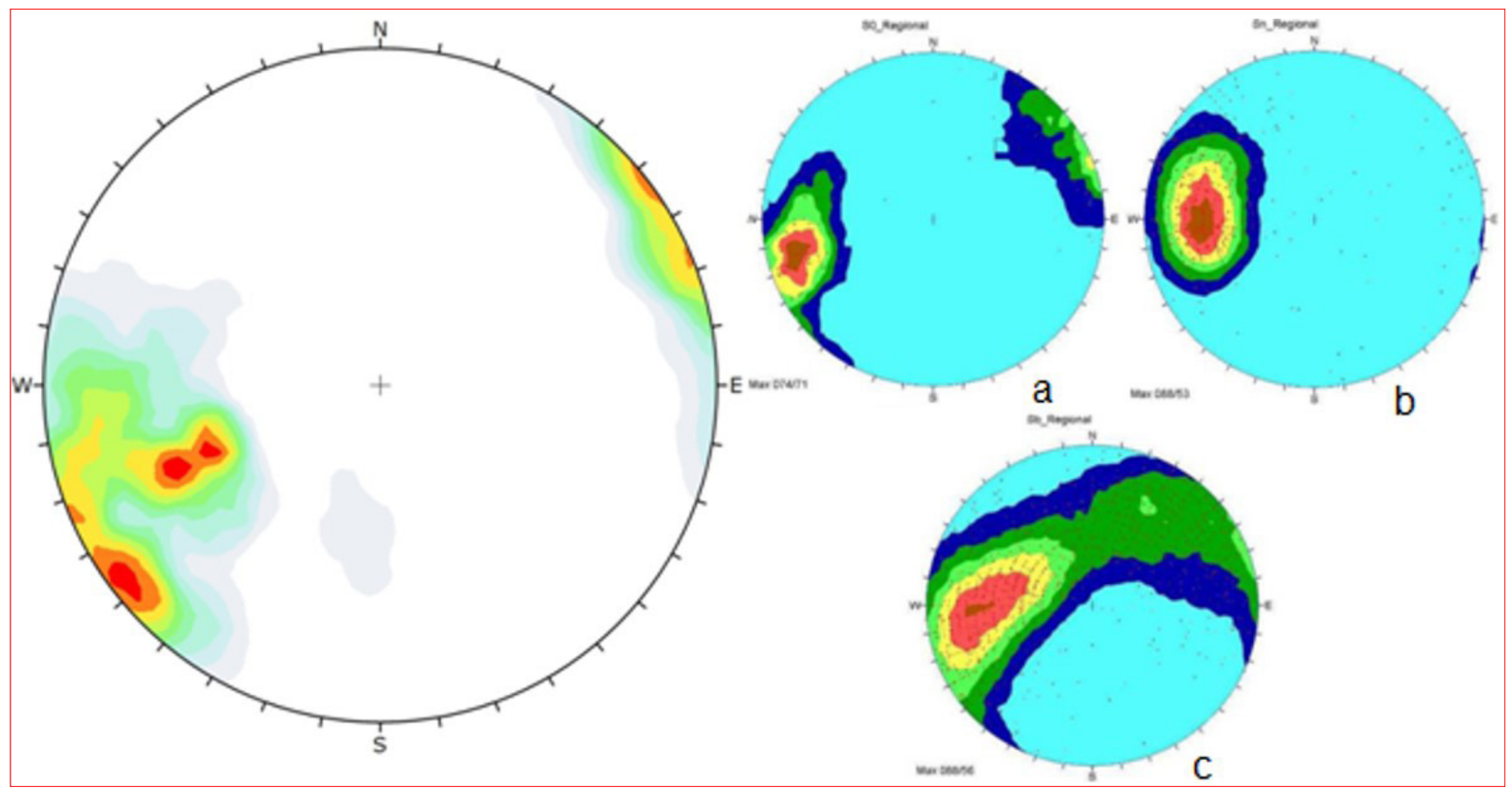

Figura 8. Estereogramas mostrando os dados obtidos por OTV (à esquerda) e as três estruturas principais na Mina do Tamanduá (à direita). Legenda: a - Acamadamento; b - Foliação; c - Bandamento Principal.

Fonte: ?

\subsection{Comparação de Análises Cinemáticas}

A seguir é feita uma comparação entre os dados cinemáticos obtidos em levantamentos geológicos de superfície nas áreas deste estudo, os quais encontram-se registrados em Anon. (2008) e Anon. (2012), e os dados processados a partir das imagens geradas por OTV.

As análises cinemáticas em Gongo Soco foram efetuadas nos três domínios nos quais foram executados os furos coletores de imagens de OTV, denominados aqui genericamente de domínios $\mathrm{A}$, B, e C. Na Mina Tamanduá, realizou-se a análise no Domínio Oeste. Em ambos os casos foi utilizada a metodologia de Markland (Mah et al., 2004) para análise de rupturas. Os ângulos de atrito utilizados para construção do cone de atrito foram de $25^{\circ}$ e $35^{\circ}$, para a Mina Gongo Soco, e $36^{\circ}$ para a Mina do Tamanduá, seguindo os valores usados em Anon. (2008) e Anon. (2012), onde foram analisadas as possibilidades de ocorrência de rupturas planares, em cunha e tombamento, considerando-se todas as estruturas planares levantadas nas minas.

Na Figura 9, a área vermelha corresponde à zona de instabilidade para rupturas em cunha e planar. A área marrom corresponde à zona de instabilidade para tombamentos. Os pontos correspondem às intersecções entre os planos das descontinuidades. Os pontos em verde indicam as intersecções entre planos sem potencial de ruptura e os pontos em vermelho indicam as intersecções entre os planos com potencial de ruptura em cunha. As setas vermelhas indicam as descontinuidades com potencial de ruptura planar (Anon., 2008). 


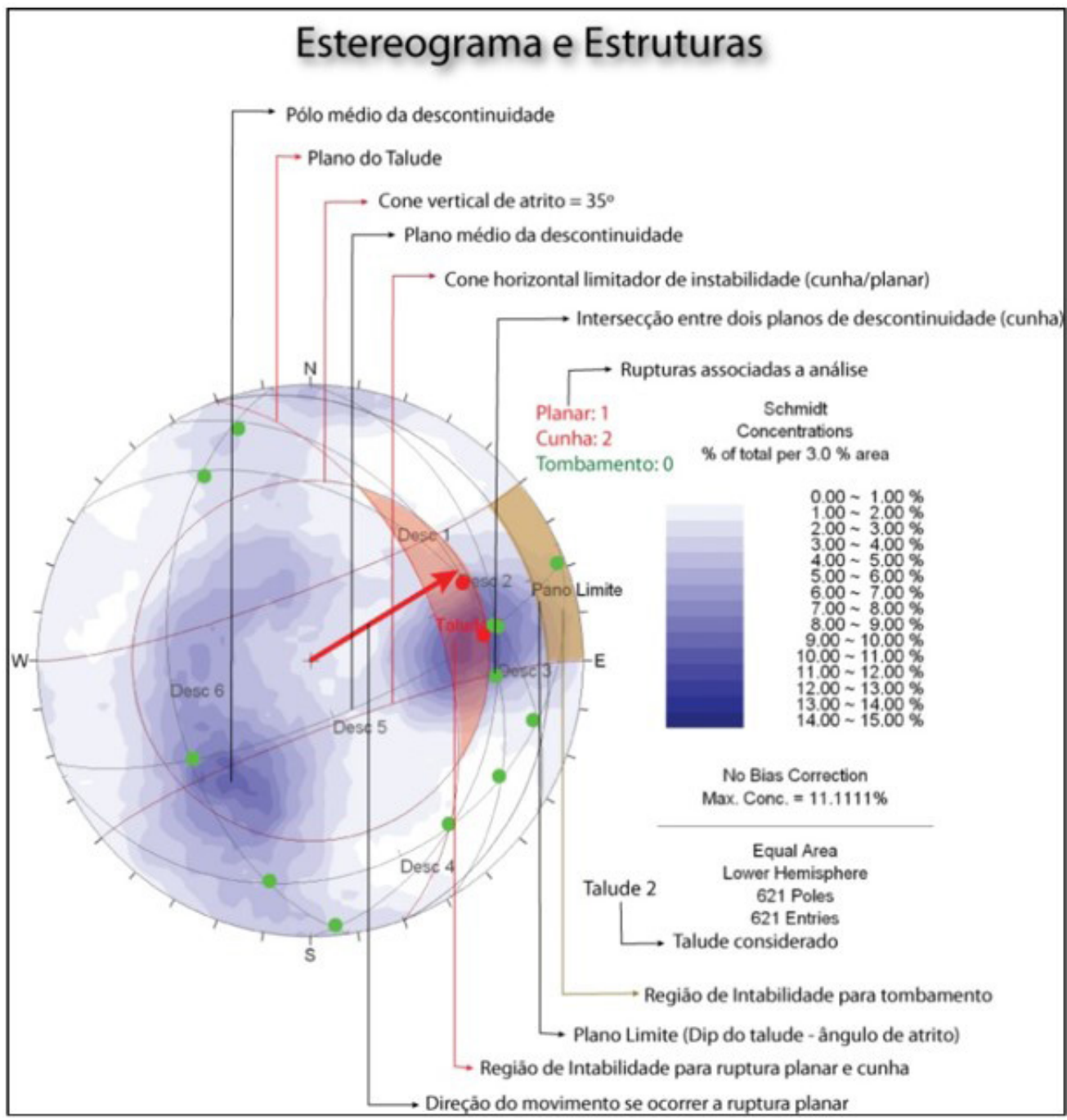

Figura 9. Identificação dos elementos considerados na análise cinemática.

Fonte: Anon., 2008.

Como forma de ilustrar as comparações realizadas entre as análises cinemáticas feitas por Anon. (2008) e as análises derivadas de OTV, para o Furo GSOFG00023 no domínio C da Mina Gongo Soco, segue na Figura 10 as análises cinemáticas feitas por Anon.(2008) e na Figura 11 as análises cinemáticas para o mesmo domínio, feitas pela equipe da UFRGS.

Foram considerados três planos de talude $(135 / 60,180 / 60$ e 220/60). Para os três planos foram realizadas análises para os ângulos de atrito igual a $25^{\circ}$ e $35^{\circ}$. O talude $135 / 60$ apresentou duas situações favoráveis ao desenvolvimento de ruptura planar (para Sb), uma para o ângulo de atrito igual a $25^{\circ}$ e outra para o ângulo igual a $35^{\circ}$ (Figura 10). A análise para o talude 180/60 para os dois ângulos de atrito, deu favorável ao desenvolvimento de rupturas planares (para $\mathrm{Sb}$ ) e a rupturas em cunhas (intersecção entre a $\mathrm{Sb}$ e $\mathrm{Sn+1}$ ) (Figura 10). Por último, a análise cinemática para o talude 220/60 deu condições favoráveis ao desenvolvimento de rupturas em cunha para os dois ângulos de atrito (intersecção entre a Sb e $\mathrm{Sn+1}$ (Figura 10). 


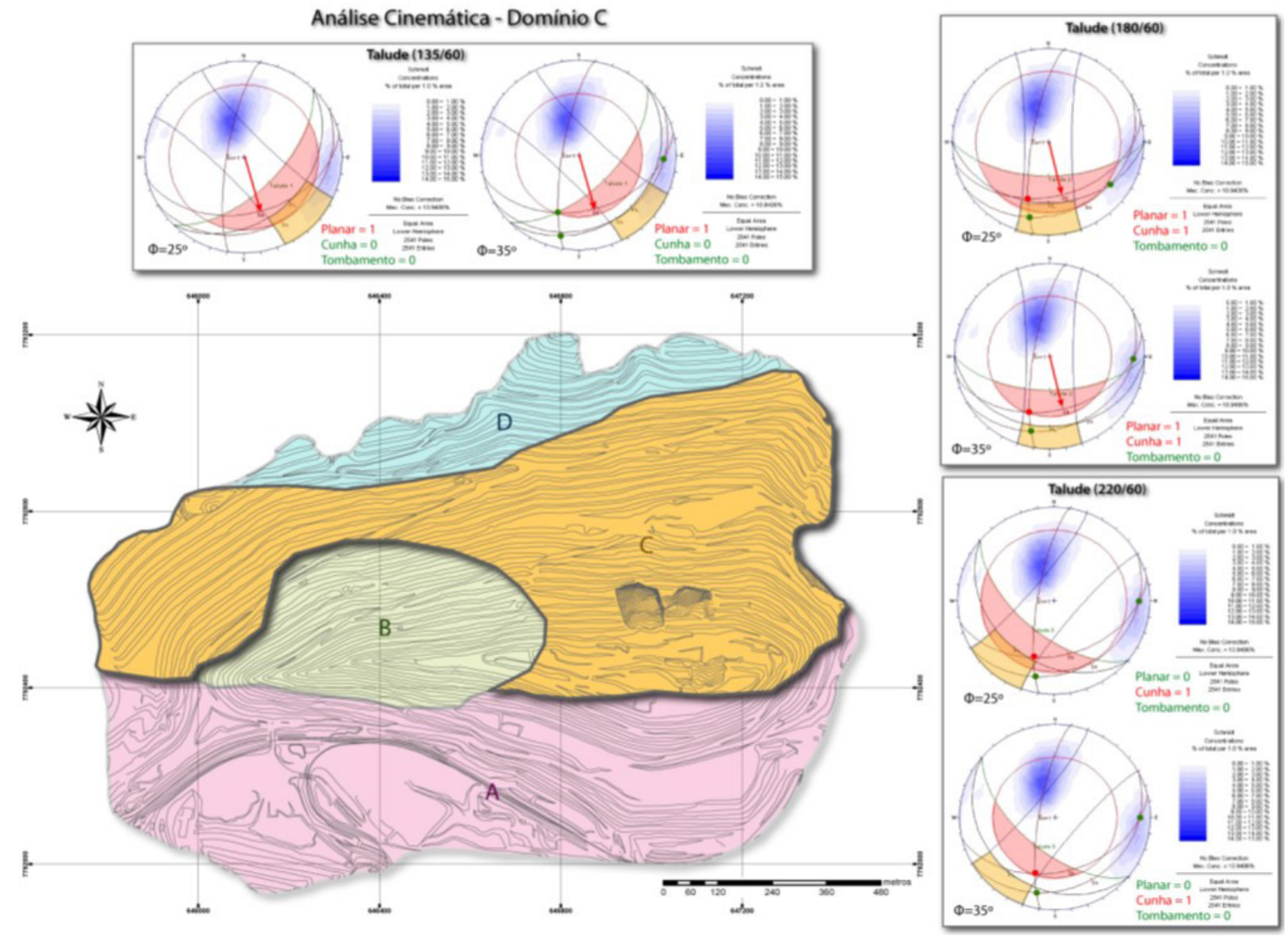

Figura 10. Análise cinemática do Domínio C, de acordo com Anon.(2008).

Fonte: Anon., 2008.

A análise cinemática do Furo GSOFG00023, localizado no domínio $C$, foi realizada baseada em três planos de talude médios $\left(135^{\circ} / 60^{\circ}, 180^{\circ} / 60^{\circ}\right.$ e $220^{\circ} / 60^{\circ}$ ). Para os três foram realizadas análises considerando o ângulo de atrito igual a $25^{\circ}$ e igual a $35^{\circ}$. Para cada talude médio foram avaliadas as possibilidades de ruptura planar, em cunha, tombamento de deslocamento circular ou de base. São apresentadas a seguir as imagens que se referem à possibilidade mais crítica, ou seja, a maior possibilidade de ruptura dentre os parâmetros com possibilidade de serem controlados (tipo de ruptura e ângulo de atrito).
O talude $135^{\circ} / 60^{\circ}$ (Figura 11a) apresenta a probabilidade de deslocamento em cunha, com $36,1 \%$ de possibilidade, para um ângulo de atrito de $25^{\circ}$. A análise cinemática para o talude $180^{\circ} / 60^{\circ}$ (Figura 11b) foi favorável ao desenvolvimento de ruptura do tipo tombamento (para o $\mathrm{Sb})$ para os dois ângulos de atrito, com a probabilidade de queda atingindo $62,37 \%$, para o ângulo de atrito de $35^{\circ}$. A análise cinemática para o talude $220^{\circ} / 60^{\circ}$ (Figura 11c) foi favorável ao desenvolvimento de ruptura do tipo cunha (para o $\mathrm{Sb}$ ) para os dois ângulos de atrito, com a probabilidade de queda atingindo $28,12 \%$ para o ângulo de $25^{\circ}$. 

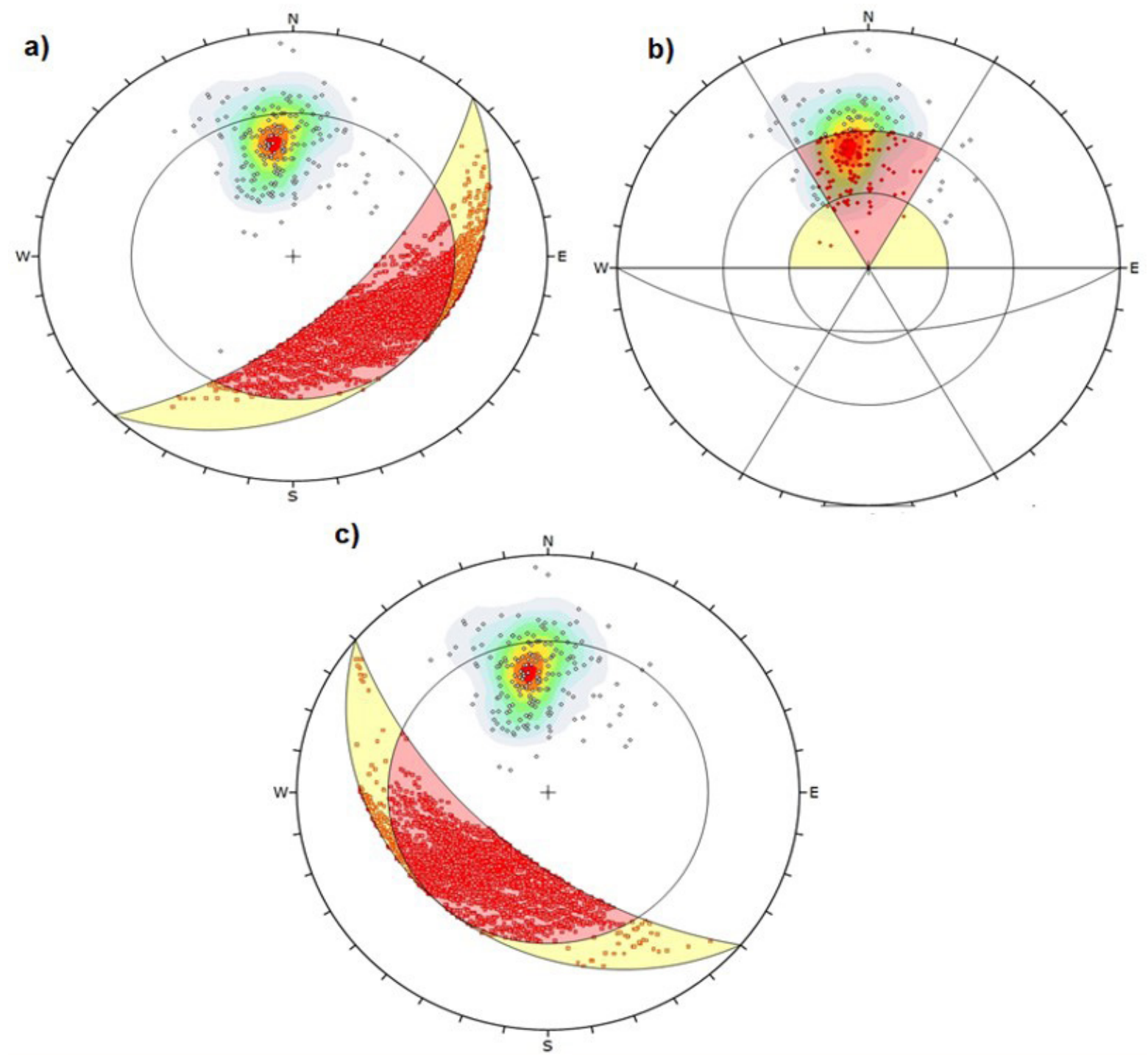

Figura 11. Análises feitas a partir das imagens de OTV. a) Análise cinemática do Domício C, talude médio $135^{\circ} / 60^{\circ}$, ângulo de atrito $25^{\circ}$; b) Análise cinemática do Domício C, talude médio $180^{\circ} / 60^{\circ}$, ângulo de atrito $35^{\circ}$; c) Análise cinemática do Domício C, talude médio $220^{\circ} / 60^{\circ}$, ângulo de atrito $25^{\circ}$.

Fonte: Anon., 2008.

A seguir é apresentado um resumo comparativo entre os resultados obtidos com as análises cinemáticas geradas pelas marcações efetuadas nas imagens produzidas pelo televisionamento dos furos e os resultados apresentados em Anon. (2008) e Anon. (2012). As Tabelas 1 e 2 trazem estas comparações. A Tabela 1 retrata as análises e os principais resultados da Mina Gongo Soco, ao passo que a Tabela 2 refere-se aos principais resultados da Mina Tamanduá. Nota-se que a maioria das rupturas apresentadas na análise realizada com OTV indica para a possibilidade de tombamento. Esta diferença entre resultados pode levar a uma conclusão precipitada de que os resultados apresentados pela análise de campo e a análise de dados gerados pela sonda podem não ser compatíveis. Comparando os estereogramas gerados em Anon. (2008 e 2012) com as respectivas estruturas principais e os estereogramas gerados pela análise de dados do OTV pode-se notar uma semelhança visual entre os estereogramas.

Mesmo que não seja possível diferenciar os tipos de estruturas marcadas nas imagens geradas pelo OTV, é possível sim afirmar que estas marcações estão compreendidas nas estruturas principais, pela comparação entre estereogramas. 
Tabela 1. Análise comparativa entre resultados OTV e levantamentos de superfície (Anon., 2008) na Mina Gongo Soco.

\begin{tabular}{|c|c|c|c|c|c|}
\hline FURO & DOMÍNIO & TALUDE & $\begin{array}{l}\text { ANGULO DE } \\
\text { ATRITO }\end{array}$ & TIPO DE RUPTURA - OTV & $\begin{array}{l}\text { TIPO DE RUPTURA - } \\
\text { Levant. superfície }\end{array}$ \\
\hline \multirow{6}{*}{ GSO00023 } & \multirow{6}{*}{ Domínio C } & \multirow{2}{*}{$135 / 60$} & 25 & Cunha & Planar \\
\hline & & & 35 & Tombamento & Planar \\
\hline & & \multirow{2}{*}{$180 / 60$} & 25 & Tombamento & Planar e Cunha \\
\hline & & & 35 & Tombamento & Planar e Cunha \\
\hline & & \multirow{2}{*}{$220 / 60$} & 25 & Cunha & Cunha \\
\hline & & & 35 & Cunha & Cunha \\
\hline \multirow{4}{*}{ GSO00025 } & \multirow{4}{*}{ Domínio B } & \multirow{2}{*}{$020 / 60$} & 25 & Tombamento & Sem Possibilidades \\
\hline & & & 35 & Tombamento & Sem Possibilidades \\
\hline & & \multirow{2}{*}{$150 / 60$} & 25 & Tombamento & Planar e Cunha \\
\hline & & & 35 & Tombamento & Planar \\
\hline \multirow{4}{*}{ GSO00027 } & \multirow{4}{*}{ Domínio A } & \multirow{2}{*}{$295 / 60$} & 25 & Tombamento & Sem Possibilidades \\
\hline & & & 35 & Tombamento & Sem Possibilidades \\
\hline & & \multirow{2}{*}{$350 / 60$} & 25 & Tombamento & Tombamento \\
\hline & & & 35 & Tombamento & Tombamento \\
\hline
\end{tabular}

Tabela 2. Análise comparativa entre resultados OTV e Anon. (2012): possibilidades de rupturas para cada talude no Domínio Oeste (entre parenteses a segunda maior probabilidade), Subdomínio Itabirito Friável. Mina Tamanduá.

\begin{tabular}{ccc}
\hline Talude & Anon. (2012) & OTV - FUROS 22 e 69 \\
\hline $\mathbf{1 4}$ & Sem possibilidades & Tombamento \\
$\mathbf{1 5}$ & Sem possibilidades & Tombamento \\
$\mathbf{1 9}$ & Planar e Cunha (duas possibilidades para cada) & Cunha \\
$\mathbf{2 0}$ & Planar e Cunha & Tombamento (Cunha) \\
$\mathbf{2 1}$ & Cunha (duas possibilidades) & Tombamento \\
$\mathbf{2 3}$ & Cunha (duas possibilidades) & Tombamento (Cunha) \\
$\mathbf{2 6}$ & Planar e Cunha (duas possibilidades para cada) & Tombamento (Cunha) \\
$\mathbf{3 0}$ & Planar e Cunha (duas possibilidades para cada) & Tombamento (Cunha) \\
\hline
\end{tabular}

\subsection{Declinação Magnética}

Durante a aquisição de dados de OTV, o posicionamento das imagens apresentadas é orientado de acordo com o norte magnético da Terra, em função do uso de magnetômetros para a orientação da sonda. Conforme Oliveira (2015), a aquisição das imagens pode ser realizada considerando-se o norte magnético, e apenas no processamento delas é adicionada a declinação magnética, de modo a obter-se a orientação final com relação ao norte geográfico. Esta sistemática foi seguida no presente caso. Desta forma, após a marcação das estruturas geológicas nas imagens, a correção da declinação magnética foi realizada no dip direction das estruturas descontando-se a diferença entre o eixo magnético, medido pela sonda, e o eixo do norte verdadeiro das mesmas. A declinação magnética assumida aqui foi de $23,5^{\circ}$. 


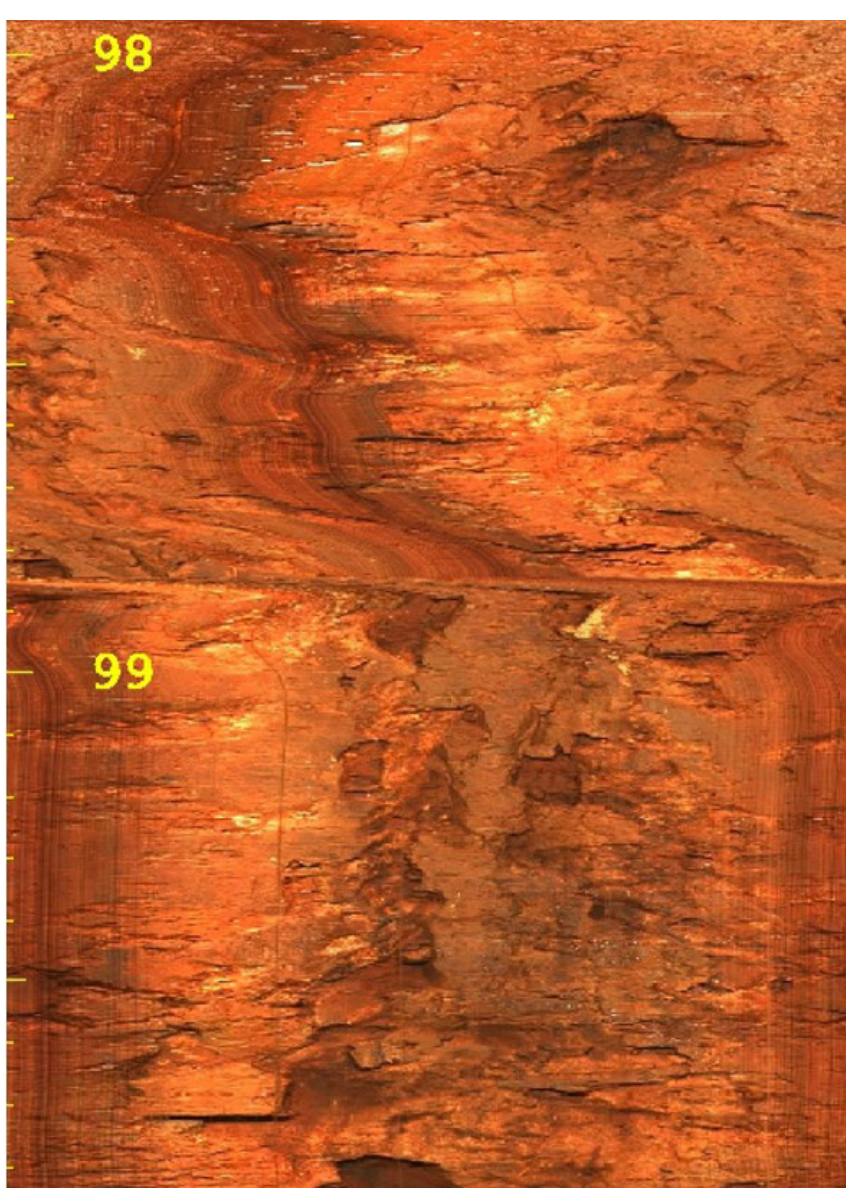

Figura 12. Imagem de OTV mostrando, entre 98 e 99 metros de profundidade, a influência de material magnético na leitura. A partir de 99 metros, essa influência desaparece, permitindo a melhor análise da imagem.

Fonte: ?

$\mathrm{Na}$ aquisição de dados, a equipe usou uma sonda de susceptibilidade magnética para apontar possíveis zonas de distorções nas imagens pela presença de minerais de alta susceptibilidade magnética (magnetita, essencialmente). Nos trechos onde a influência magnética foi percebida, os valores máximos e mínimos de susceptibilidade ficaram entre 0,009 e 0,046 (sistema cgs de unidades), e foram considerados dentro do esperado para as litologias investigadas (Dearing, 1999). A análise visual das imagens da sonda OTV mostrou que em nenhum dos furos houve grandes distorções causadas pelo magnetismo das rochas. Apenas em alguns trechos de pequeno comprimento (poucos metros) nos furos de sondagem, percebeu-se a influência de minerais magnéticos (Figura 13), os quais não tiveram interferência nos resultados gerais.

\section{CONCLUSÕES}

Este estudo permite afirmar que é possível retirar informações úteis sobre a geologia estrutural e aspectos geotécnicos de um maciço rochoso via imagens de OTV. Reitera-se o potencial do OTV como uma ferramenta de apoio, mas não um substituto para a sondagem testemunhada, consistindo em um importante aliado na obtenção de informações não visíveis em amostras diretas. É importante ressaltar também o benefício oferecido pelo OTV em termos do posicionamento de estruturas geológicas. Fazendo um tratamento cuidadoso das imagens, pode-se orientar as estruturas com mais segurança que a sondagem orientada. O azimute de descontinuidades e outras estruturas ficam mais próximas do valor verdadeiro quando estimadas por OTV. Desta forma, é totalmente viável a produção de estereogramas com as estruturas marcadas nas imagens, os quais terão grande semelhança com estereogramas gerados a partir de levantamentos de campo efetuados em superfície ou sondagens orientadas, conforme apresentado no tópico 4 (figuras 8 e 9).

Outro ponto de discussão são as possíveis influências de materiais com alta susceptibilidade magnética sobre as imagens. Observando-se o fato de que a sonda OTV utiliza magnetômetros para marcar seu geoposicionamento, a presença de material magnético pode influenciar neste posicionamento e gerar distorções nas imagens produzidas. Durante a aquisição e processamento de dados verificaram-se poucas situações de distorção. Como é apresentado no tópico 4.3, no presente caso não foram encontrados materiais com susceptibilidade suficientemente alta para produzir distorções nas imagens de modo a interferir nas análises.

Embora o uso do televisionamento de furos introduza alguns cuidados operacionais que tendem a tornar mais lenta a atividade de sondagem (p.ex. limpeza do furo, tratamento do fluido com floculante, etc.), acredita-se que a utilização do OTV pode ser valiosa na aquisição de informações geológico-geotécnicas em empreendimentos de mineração em locais como o Quadrilátero Ferrífero-MG. 


\section{AGRADECIMENTOS}

Os autores agradecem fortemente à empresa VALE S.A. pelo suporte disponibilizado para a execução deste estudo.

\section{REFERÊNCIAS}

ANON., Mapeamento Lito-Estrutural e Geomecânico da Mina Gongo Soco, BVP-Engenharia, Mina Gongo Soco - VALE, 2008.

ANON., Avaliação Geotécnica da Geometria dos Taludes das Cavas Finais das Minas DIFL, Avaliação Geotécnica da Cava Final da Mina Tamanduá, BVP-Engenharia, 2012.

BAILLOT, R. T., TELEVISAMENTO $360^{\circ}$ DAS PAREDES DE FUROS DE SONDAGEM, Empresa Alphageos, Divulgação Técnica, 2012.

BAILLOT, R.T., Colas, R., Barton, N., Abrahão, R. e Ribeiro Júnior, A. Comparing $360^{\circ}$ Televising of Drill Hole Walls with Core Logging. Proc.

International Site Investigation Conf, Portugal. 2004.

BLAKE, J.R., Application of borehole imagery in iron ore: examples from Mount Whaleback, Western Australia. Applied Earth Science (Trans. Inst. Min. Metall. B), VOL 119, NO 3. 2010.

CHUNG, M.C., HSU, S.M., KU, C.Y., TAN, C.H., CHI, S.Y.; Geotechnical Engineering Research Center, Sinotech Engineering Consultants, Inc., Taipei, Taiwan. 2008.
DEARING, J., Environmental Magnetic Susceptibility: A Guide to Using Bartington MS2 System. 1999.

FREDRICK, F., Nguyen, T., Seymour, C., Dempers, G., Geotechnical data from optical and acoustic televiewer surveys. The AusIMM Bulletin - Journal of the Australasian Institute of Mining and Metallurgy, n.5, October. 2014.

GWYNN, X.P.; BROWN, M.C.; MOHR, P.J.; Combined use of Tradicional Core Logging and Televiewer Imaging for Pratical Geotechnical data Collection, SRK Consulting (UK) LTD, United Kingdom, September 2013.

MAH, C. W. e Wyllie, D.C., Rock slope engineering: civil and mining. 4th ed, 2004.

MILLOY, Sophie F., McLean Katie e McNamara David D., Comparing Borehole Televiewer Logs with Continuous Core: An Example from New Zealand, Proceedings World Geothermal Congress, Australia, 2015.

OLIVEIRA, D.G.G., Televisionamento óptico de sondagens - proposta metodológica para execução e suas aplicações em obras subterrâneas, Dissertação - IGc/USP, São Paulo, 2015.

ROBERTSON GEOLOGGING, OPTV USER MANUAL, 2014.

THOMAS, R.D.H.; NEILSEN, J.M.; WILSON, H.F.; LAMB,P.; Structural Interpretation from Televiewers Surveys, Australian Centre for Geomechanics, Perth, Australia, 2015. 